Oikos 120: 1005-1012, 2011

doi: $10.1111 / j .1600-0706.2010 .18844 . x$

(C) 2011 The Authors. Oikos (C) 2011 Nordic Society Oikos

Subject Editor: Hamish McCallum. Accepted 11 November 2010

\title{
Predator-induced modifications to diving behavior vary with foraging mode
}

\author{
Aaron J. Wirsing, Michael R. Heithaus and Lawrence M. Dill \\ A. J. Wirsing (wirsinga@u.washington.edu), School of Forest Resources, Box 352100, Univ. of Washington, Seattle, WA 98195, USA. - \\ M. R. Heithaus, Dept of Biological Sciences, Florida International Univ., Biscayne Bay Campus, 3000 NE 151 Street, North Miami, \\ FL 33181, USA. - L. M. Dill, Dept of Biological Sciences, Simon Fraser Univ., 8888 University Drive, Burnaby, BC V5A 1S6, Canada.
}

\begin{abstract}
Breath-hold divers are strongly interacting species whose top-down influence on aquatic communities is shaped by factors governing their diving decisions. Although some of these factors (e.g. physiological constraints, energetic needs) have been scrutinized, the possibility that predation risk influences diving behavior has been largely overlooked, and no study to date has asked if anti-predator responses by divers depend on foraging mode. We contrasted dive cycle changes by herbivorous dugongs Dugong dugon using two foraging tactics - cropping, which always permits anti-predator vigilance, and excavation, which limits surveillance at depth - in response to temporal variation in tiger shark Galeocerdo cuvier abundance. Dugongs responded to increasing shark abundance (one component of predation risk) by diving more frequently without changing their surface times and thereby spending a greater proportion of time at the surface, but only while excavating. When threatened, in other words, excavating dugongs sacrificed foraging time at depth to facilitate shark detection. In contrast, cropping dugongs at risk from sharks were able to continue diving and foraging normally. By implication, future studies should consider the influence of predation risk on diving decisions, even by large-bodied species, and the possibility that behavioral responses by divers to predators may vary with foraging mode.
\end{abstract}

Air-breathing aquatic foragers (e.g. marine mammals and reptiles, diving birds) must balance the need for oxygen recovery at the surface and resource exploitation at depth (Houston and Carbone 1992). Accordingly, their diving behavior is widely assumed to be a product of the interplay between these twin concerns (Kramer 1988, Carbone and Houston 1996, Thompson and Fedak 2001). Yet, most breath-hold divers are also faced with the prospect of becoming a meal themselves, so they may alter their diving behavior in order to mitigate predation risk (Heithaus and Frid 2003). Despite growing theoretical support (Frid et al. 2006, 2007a, 2008, 2009), this possibility has received little empirical evaluation (Frid et al. 2007a, Dunphy-Daly et al. 2010) and continues to be ignored (Frid et al. 2007b). Given that ecological interactions of divers are spatially and temporally structured by their diving decisions (Boyd 1997) and that divers are often species whose absence or rarity can lead to ecosystem transformation (i.e. 'strongly interactive species', sensu Soulé et al. 2005), studies of diving under predation risk should yield valuable insights about aquatic community dynamics. They will also improve our understanding of the influence that aquatic predators have on populations of their air-breathing prey and community properties by inducing changes in mesoconsumer (i.e. mid-trophic level predator or herbivore) diving behavior. A better understanding of these top-down effects has become vital because many large-bodied aquatic predators appear to be in worldwide decline (Pauly et al. 1998, Myers and Worm 2003).

The risk of predation experienced by prey individuals can vary with foraging mode (Bednekoff and Lima 1998, Kaby and Lind 2003, Guillemain et al. 2007). For example, foraging tactics that are complex (Kaby and Lind 2003) or obstruct vision (Krause and Godin 1996) are more likely to impede detection and escape from predators than those that facilitate surveillance. Consequently, individuals using inherently dangerous foraging modes may be especially responsive to the presence of predators and compensate by investing more heavily in other forms of anti-predator behavior (e.g. avoidance, altered activity patterns). Among aquatic air breathers, for instance, we might expect individuals employing risky foraging tactics to dive in a manner that confers greater protection from predators than conspecifics using safer feeding modes. Here, we present an unprecedented test of this hypothesis using diving dugongs Dugong dugon foraging under temporally variable threat of predation by tiger sharks Galeocerdo cuvier in the subtropical seagrass ecosystem of Shark Bay, Australia.

Dugongs forage either by stripping clusters of leaves from the branching stems of seagrass plants (cropping) or by removing entire seagrass plants from the substrate to consume both leaves and rhizomes (excavation) (Aragones et al. 2006, Wirsing et al. 2007a). Excavation is likely more 
profitable because it enables dugongs to add important nutrients that are plentiful in rhizomes (e.g. organic carbon) to the high concentrations of nitrogen found in seagrass leaves (Marsh et al. 1982, de Iongh et al. 1995). However, this tactic also involves extended periods of digging, during which time vigilance is compromised, and creates huge sediment plumes that further obscure visibility and may actually draw the attention of predators. Conversely, the cropping tactic is presumably less profitable but does not cloud the water and allows for frequent visual scans between bites. Thus, dugongs engaged in excavation likely pay the cost of increased predation risk from tiger sharks, which are able to detect prey in murky water through mechano- (lateral line system) and/or electroreception (Wirsing et al. 2007a). The magnitude of this cost in Shark Bay changes over time, however, because tiger shark abundance in the bay fluctuates between a high in February and a low in July each year (Wirsing et al. 2006). Under the assumption that diving by dugongs is sensitive to the threat posed by tiger sharks, we predicted that excavating dugongs would respond to rising shark abundance (i.e. increasing probability of predator encounters and therefore need for anti-predator investment) with compensatory adjustments to their diving behavior to a greater extent than those foraging with the cropping tactic. In Shark Bay, foraging dugongs that detect the approach of a shark are able to flee from shallow seagrass banks into deeper waters that offer little food but allow for increased maneuverability and, consequently, a higher chance of surviving an attack (Wirsing et al. 2007b). Thus, dugongs in the act of excavation are presumably at greatest risk from sharks when they are digging seagrass plants up from the substrate, and their vision is obscured by suspended sediment, and safest while breathing at the surface, where they expose only their rostrum to the air and are able to continuously scan their surroundings. Accordingly, we expected excavating dugongs to compensate for increasing shark abundance by making more frequent trips to the surface (i.e. by spending a reduced portion of their time digging for seagrass rhizomes at depth).

\section{Material and methods}

\section{Study site}

This study was conducted over the course of four years (2002-2004, 2006) in the Eastern Gulf of Shark Bay, offshore of the Monkey Mia Dolphin Resort ( $\left.25^{\circ} 45^{\prime} \mathrm{S}, 113^{\circ} 44^{\prime} \mathrm{E}\right)$. The Shark Bay region is protected as a World Heritage Area and is occupied by 10 000-14 000 dugongs (Gales et al. 2004), many of which forage in our study area (Wirsing et al. 2007b). The dugong's only known predator in the area is the tiger shark.

\section{Predator abundance}

Catch rates provide a reliable measure of tiger shark abundance in Shark Bay (Heithaus 2001, Wirsing et al. 2006). Over the course of the four-year study, we caught tiger sharks $(\mathrm{n}=211)$ on single-hook drumlines baited primarily with Australian salmon Arripis truttaceus and deployed between dawn and dusk in six fishing zones throughout the study area $\left(\sim 160 \mathrm{~km}^{2}\right)$ (Wirsing et al. 2006, Wirsing et al. unpubl.). Although our sampling effort was intensive, we did not fish for sharks every day. Thus, we fit our catch rate data with a sinusoidal function using maximum likelihood (Wirsing et al. 2007b). This modeling procedure, which used a period of one year and assumed a Poisson error distribution because our data consisted of integer values for the number of sharks caught per day, allowed us to predict the annual trend in daily shark catch rates and, as a result, furnished a robust estimate of relative tiger shark abundance for each day of the year (years pooled). Because tiger sharks under $3.0 \mathrm{~m}$ in length (TL) are unlikely to pose a threat to adult dugongs (Wirsing et al. 2007b), only sharks larger than this were used to estimate daily abundance $(\mathrm{n}=78)$. However, the inclusion of smaller tiger sharks does not change the results presented below. Although absolute tiger shark abundance in our study area varies with habitat, being consistently higher over shallow banks than in deeper areas (Heithaus et al. 2006), the annual trend in shark abundance does not.

\section{Dugong diving behavior}

We assessed the diving behavior of individual dugongs using focal animal follows ( $\mathrm{n}=56$; Altmann 1974) conducted between January and May, an interval during which both foraging tactics are used (Wirsing et al. 2007a) and tiger shark abundance drops from its peak to relatively low levels (Wirsing et al. 2006). Individual adults sighted randomly along transect passes over shallow seagrass banks (see Wirsing et al. 2007b for detailed transect methods) were chosen for focal observation, reducing the possibility that starting positions were spatially biased (Heithaus et al. 2006). Follows were only conducted in Beaufort wind conditions $\leq 1$ to ensure that our observations were reliable. Focal animals were approached at slow speed $\left(\sim 1 \mathrm{~km} \mathrm{~h}^{-1}\right)$ and then allowed to acclimate to our vessel (a $4.5 \mathrm{~m}$ runabout) for $5 \mathrm{~min}$ from a distance of roughly $50 \mathrm{~m}$; behavioral observations were then made from a distance of $10-20 \mathrm{~m}$. This method of observation is minimally invasive: focal individuals almost never altered their behavior or moved in response to our approach and moved freely about the vessel, suggesting that we were not perceived as a distraction or a threat. Dugongs that did change their behavior or move as we approached $(\mathrm{n}=5)$ were not followed.

During each follow, we recorded water depth $(\mathrm{m})$ and the focal individual's position (with a GPS), dominant behavioral state (foraging or not), and dominant foraging mode (excavation or cropping) every two minutes. Behavioral states and foraging modes were usually determined via direct observation of the submerged animal or, when subsurface activity could not be seen, using diagnostic behavior and characteristics at the surface (Chilvers et al. 2004): foraging dugongs can be distinguished from those that are resting or travelling based on their slow pace, irregular surface intervals, and tendency to bring more of the body out of the water in preparation for a deeper dive, while cropping dugongs can be differentiated from excavating individuals based on their meandering search paths and the absence of a sediment plume (note that cropping was never inferred solely from the absence of a plume). We also recorded the timing of every breath, allowing us to calculate the total number of dives made by each focal dugong and 
the duration of each of its surface and submerged intervals. For the purposes of this study, we considered a follow to be over when the focal individual left shallow seagrass bank habitat (depths $\leq 4.5 \mathrm{~m}$ ) for deeper water. The water depth range over which follows were undertaken was $1.5-4.5 \mathrm{~m}$, and individual focal dugongs remained at relatively constant water depths during follows (mean depth range per follow $=1.06 \mathrm{~m}, \pm S D=0.92 \mathrm{~m}$ ). During follows we noted unique scars and markings to ensure that no individual was observed more than once, and restricted our analysis to follows that featured at least $20 \mathrm{~min}$ of continuous foraging activity. Focal observation periods subjected to analysis averaged $41.1 \mathrm{~min}( \pm \mathrm{SD}=18.6 \mathrm{~min})$.

\section{Statistical analysis}

We considered a dive cycle to consist of a dive (submerged) interval and the post-dive surface interval; the number of dive cycles recorded during follows ranged from 13 to 56 . We analyzed four dive cycle parameters that could change in response to variation in predation risk: (1) mean time spent at the surface (i.e. average surface interval duration, TAS); (2) mean time spent at depth (i.e. average submerged interval duration, TAD); (3) diving rate (dives per hour); and (4) mean dive-pause ratio (i.e. the ratio of submerged time to surface time, DPR). Though correlated, these dive cycle components were analyzed as separate dependent variables so that we could identify which ones, if any, were responsive to predation danger. For all four dependent variables, each focal dugong contributed a single mean value $(\mathrm{n}=38$ cropping individuals; $\mathrm{n}=18$ excavating individuals). Data for time at the surface, time at depth, and dive-pause ratio were normalized using $\log$ transformations (Shapiro-Wilks test: TAS, $\mathrm{W}=0.965, \mathrm{p}=0.104$; TAD, $\mathrm{W}=0.987, \mathrm{p}=0.816$; DPR, $\mathrm{W}=0.966, \mathrm{p}=0.115$ ) and then fit using general linear models, while data for diving rate were modeled using Poisson regression with a log link function. Explanatory variables included in all models were foraging tactic (cropping or excavation), relative tiger shark abundance (estimated sharks caught $\mathrm{h}^{-1}$ ), mean water depth (to account for differences in travel time to and from the bottom), and year (2002-2004, 2006). We also always included the interaction between foraging tactic and shark abundance to test for divergent diving behavior by cropping and excavating dugongs in response to changing predation risk; other possible interactions were excluded from final models if they were non-significant. Effects of explanatory variables were deemed significant if their $95 \%$ confidence interval did not overlap zero (Johnson 1999).

In Shark Bay, tiger shark abundance and ocean temperature covary positively (Heithaus 2001). Thus, we needed to ensure that any observed statistical links between changing shark abundance and dugong dive cycle features were not confounded by an underlying relationship between dugong diving and water temperature. Accordingly, because strong multicollinearity precluded the inclusion of these two variables in the same model, we built competing models of each of the four dependent variables in which estimates of tiger shark abundance were replaced with measures of water temperature (taken during each follow). We compared the fit of shark- and temperature-based models of each dependent variable using Akaike's information criterion, corrected for small sample size ( $\mathrm{AIC}_{\mathrm{c}}$, Burnham and Anderson 2002). In performing these non-nested model comparisons, we took superiority of the shark-based model (lower $\mathrm{AIC}_{\mathrm{c}}$ ) to mean that observed statistical relationships between predation risk and diving behavior were not confounded by an underlying influence of water temperature.

To graphically depict modeled relationships between tiger shark abundance and the four diving metrics, we generated partial regression plots (Belsley et al. 2004). These plots feature residuals from regressing the dependent variable against all explanatory variables, save the one of interest, on the $y$-axis and residuals from regressing the explanatory variable of interest against the remaining explanatory variables on the $\mathrm{x}$-axis. As such, they isolate the role of particular explanatory variables within multiple regression models. That is, slopes of partial regression plots show the effect of one explanatory variable (in this case shark abundance) on the dependent variable (in this case TAS, TAD, diving rate, or DPR) after controlling for its multicollinearity with, and the effects of, other explanatory variables. For each diving metric, partial regression plots distinguish between residuals and slopes for cropping and excavating dugongs and thereby illustrate any differences in the responses of individuals using these two tactics to changing shark abundance.

\section{Results}

\section{Time at surface (TAS)}

Overall, time spent at the surface per dive cycle by dugongs foraging over shallow seagrass banks averaged 2.79 ( \pm 0.85 , $\mathrm{SD})$ seconds and did differ significantly as a function of foraging tactic (cropping, mean $=2.98 \pm 0.93 \mathrm{~s}$; excavating, mean $=2.40 \pm 0.45 \mathrm{~s}$ ), tiger shark abundance, water depth, year, and the interaction between foraging tactic and shark abundance (Table 1, Fig. 1a). Replacement of shark abundance with water temperature produced a final model of TAS with nearly identical support $\left(\triangle \mathrm{AIC}_{\mathrm{c}}=+0.002\right)$.

Table 1. General linear model of mean time at surface (TAS) per dive cycle for foraging dugongs $(n=56)$ in Shark Bay, Western Australia. A log transformation was used to normalize the dependent variable. Explanatory variables included in the final model are water depth (depth), foraging tactic (cropping versus excavation), tiger shark abundance (shark), year (2002-2004, 2006), and the interaction of tiger shark abundance and foraging tactic (shark $\times$ foraging tactic); other possible interactions were all non-significant $(95 \% \mathrm{Cl}$ overlapping zero) and therefore excluded (and note that the model is unchanged if the non-significant shark $x$ foraging tactic term is removed).

\begin{tabular}{lcc}
\hline Parameter & $\beta$ & \multicolumn{1}{c}{$95 \% \mathrm{Cl}$} \\
\hline Intercept & 0.381 & $\mathbf{0 . 1 9 6 , 0 . 5 6 5}$ \\
Depth & 0.020 & $-0.014,0.054$ \\
Foraging tactic & -0.053 & $-0.239,0.133$ \\
Shark & 0.179 & $-3.730,4.089$ \\
Shark $\times$ Foraging tactic & 0.026 & $-6.939,6.992$ \\
Year (2002) & 0.024 & $-0.111,0.160$ \\
Year (2003) & 0.027 & $-0.080,0.135$ \\
Year (2004) & 0.014 & $-0.067,0.094$ \\
Year (2006) & - & - \\
\hline
\end{tabular}

Significant relationships appear in bold. 

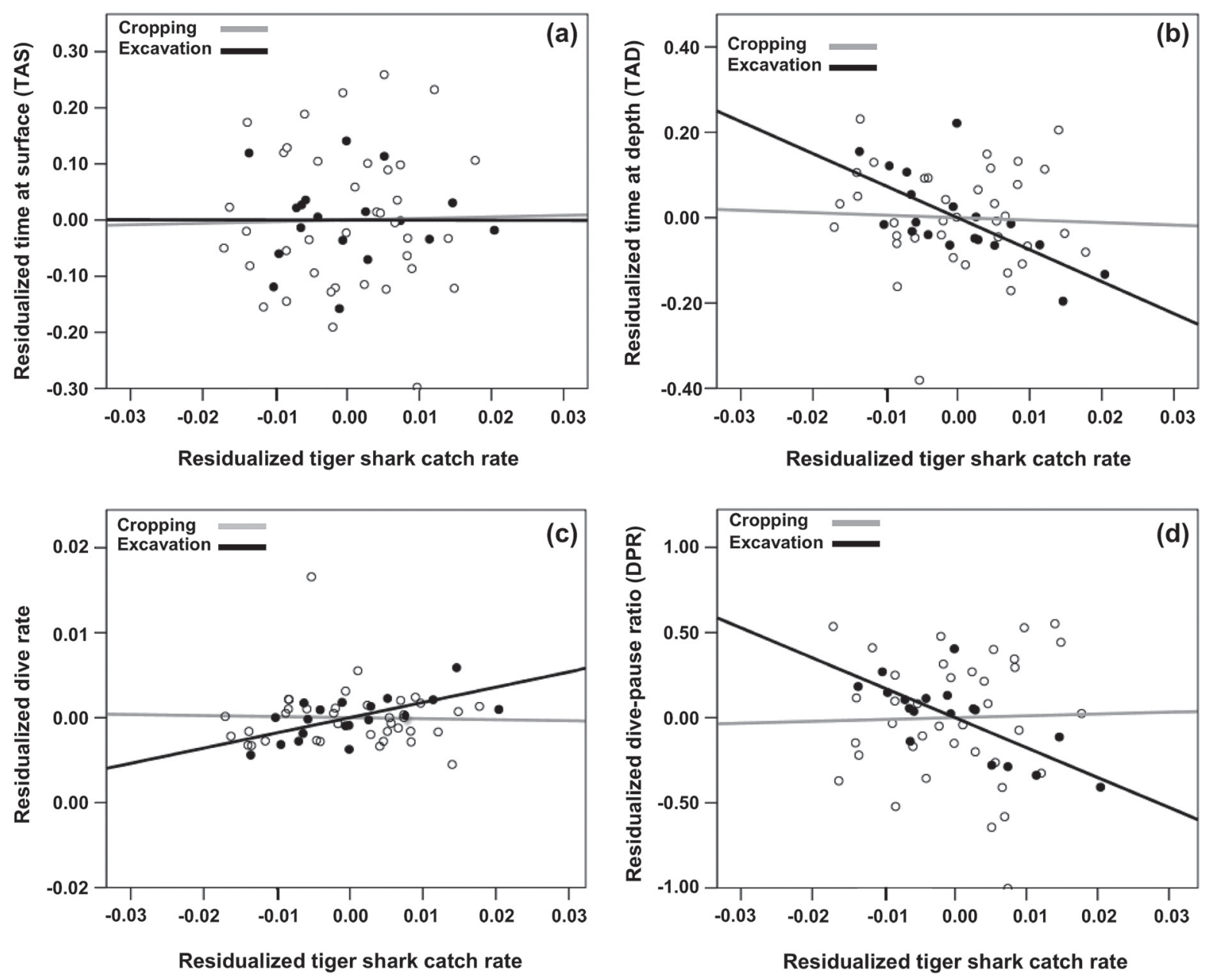

Figure 1. Partial regression plots of residuals from regressing (a) time at surface (TAS), (b) time at depth (TAD), (c) diving rate, and (d) dive-pause ratio (DPR) for diving dugongs against all explanatory variables save estimated tiger shark abundance (i.e. 'Residualized' values for the dependent variables, $y$-axis) and residuals from regressing estimated tiger shark abundance against the remaining explanatory variables ('Residualized tiger shark catch rate', x-axis). Slopes show the effect of shark abundance on each dependent variable after controlling for multicollinearity with, and the effects of, the other explanatory variables. Residuals and slopes are depicted separately for cropping (open circles, gray line) and excavating (black circles, black line) dugongs to illustrate differential responses to changing shark numbers.

\section{Time at depth (TAD)}

Time at depth per dive cycle averaged $93.34( \pm 36.40, \mathrm{SD})$ seconds overall and did not differ significantly with respect to foraging tactic (cropping, mean $=100.32 \pm 37.76 \mathrm{~s}$; excavating, mean $=78.62 \pm 29.07 \mathrm{~s}$ ), shark abundance, and year (Table 2). However, TAD did increase significantly with water depth (Table 2), and was also influenced by the interaction between foraging tactic and shark abundance: TAD was inversely related to shark abundance among excavating but not cropping dugongs (Table 2, Fig. 1b). Replacement of shark abundance with water temperature yielded a final model of $\mathrm{TAD}$ with somewhat weaker support $\left(\triangle \mathrm{AIC}_{\mathrm{c}}=+2.26\right)$.

\section{Diving rate}

The rate of diving by foraging dugongs was influenced only by water depth and the interaction of foraging tactic and shark abundance (Table 3): dugongs made fewer dives as depth increased and only excavating dugongs increased their diving rate along with rising shark abundance (Fig. 1c).
The temperature-based model of diving rate was inferior to the shark-based model $\left(\triangle \mathrm{AIC}_{\mathrm{c}}=+2.24\right)$.

\section{Dive-pause ratio (DPR)}

The dive-pause ratio characterizing foraging dugongs varied significantly as a function of water depth and the interaction between foraging tactic and shark abundance (Table 4): the proportion of the dive cycle that dugongs allocated to the post-dive surface interval decreased with increasing depth and only excavating dugongs spent relatively more time at the surface compared to time spent beneath it (i.e. decreased their DPRs) as tiger shark abundance increased (Fig. 1d). Replacement of shark abundance with temperature resulted in a model of DPR with less support $\left(\triangle \mathrm{AIC}_{\mathrm{c}}=+1.75\right)$.

\section{Discussion}

The influence of predation risk on diving by air-breathing aquatic foragers has a strong theoretical basis (Frid et al. 
Table 2. General linear model of mean time at depth (i.e. submerged, TAD) per dive cycle for foraging dugongs. A log transformation was used to normalize the dependent variable. Explanatory variables included in the final model are water depth (depth), foraging tactic (cropping versus excavation), tiger shark abundance (shark), year (2002-2004, 2006), and the interaction of tiger shark abundance and foraging tactic (shark $\times$ foraging tactic); other possible interactions were all non-significant $(95 \% \mathrm{Cl}$ overlapping zero) and therefore excluded.

\begin{tabular}{lcc}
\hline Parameter & $\beta$ & $95 \% \mathrm{Cl}$ \\
\hline Intercept & 1.679 & $\mathbf{1 . 5 1 1}, \mathbf{1 . 8 4 7}$ \\
Depth & 0.106 & $\mathbf{0 . 0 7 6 , 0 . 1 3 7}$ \\
Foraging tactic & 0.152 & $-0.018,0.321$ \\
Shark & -0.449 & $-4.016,3.118$ \\
Shark $\times$ Foraging tactic & -7.389 & $\mathbf{- 1 3 . 7 4 5 , - 1 . 0 3 4}$ \\
Year (2002) & 0.011 & $-0.113,0.135$ \\
Year (2003) & 0.000 & $-0.099,0.097$ \\
Year (2004) & 0.060 & $-0.014,0.134$ \\
Year (2006) & - & - \\
\hline
\end{tabular}

Significant relationships appear in bold.

2007b). Moreover, a number of studies have inferred that certain aspects of diving behavior may have been shaped by predation danger (e.g. nocturnal deep diving and scanning prior to surfacing by sea turtles; Hayes et al. 2001, Houghton et al. 2008). Yet, the impact of predators on diving decisions has received scant empirical attention, and changes in diving behavior triggered by varying predation risk have only rarely been demonstrated (Dunphy-Daly et al. 2010). Here, we provide the best field demonstration to date that the threat of predation can induce breath-hold divers to adjust the parameters of their dive cycles. Moreover, for the first time, we show that anti-predator alterations made by individual divers are contingent upon their foraging mode. In accord with our prediction, dugongs over shallow seagrass meadows responded to an increasing threat of tiger shark predation by diving more frequently without changing their surface times and thereby spending a smaller proportion of each dive cycle at depth, but only when using a foraging tactic excavation - that constrains anti-predator vigilance more at the ocean bottom than at the surface. Our results add to

Table 3. Generalized linear model of foraging dugong dive rate (number of dives per hour) as a function of water depth (depth), foraging tactic (cropping versus excavation), tiger shark abundance (shark), year (2002-2004, 2006), and the interaction of tiger shark abundance and foraging tactic (shark $\times$ foraging tactic); other possible interactions were all non-significant ( $95 \% \mathrm{Cl}$ overlapping zero) and not included in the final model. A Poisson error distribution served as the basis for statistical inference.

\begin{tabular}{lcc}
\hline Parameter & $\beta$ & $95 \% \mathrm{Cl}$ \\
\hline Intercept & 0.491 & $\mathbf{0 . 1 4 7 , 0 . 8 3 5}$ \\
Depth & -0.197 & $\mathbf{- 0 . 2 6 5 , - 0 . 1 2 9}$ \\
Foraging tactic & -0.299 & $-0.616,0.018$ \\
Shark & -6.704 & $-14.318,0.911$ \\
Shark $\times$ Foraging tactic & 24.880 & $\mathbf{1 3 . 8 2 9 , 3 5 . 9 3 2}$ \\
Year (2002) & -0.264 & $-0.537,0.010$ \\
Year (2003) & 0.124 & $-0.060,0.308$ \\
Year (2004) & -0.166 & $-0.299,-0.032$ \\
Year (2006) & - & - \\
\hline
\end{tabular}

Significant relationships appear in bold.
Table 4. General linear model of mean dive-pause ratio (i.e., surface time divided by dive time, DPR) per dive cycle for foraging dugongs. A log transformation was used to normalize the dependent variable. Explanatory variables included in the final model are water depth (depth), foraging tactic (cropping versus excavation), tiger shark abundance (shark), year (2002-2004, 2006), and the interaction of tiger shark abundance and foraging tactic (shark $x$ foraging tactic); other possible interactions were all non-significant (95\% Cl overlapping zero) and therefore excluded.

\begin{tabular}{lcc}
\hline Parameter & $\beta$ & $95 \% \mathrm{Cl}$ \\
\hline Intercept & 1.356 & $\mathbf{0 . 8 5 1}, \mathbf{1 . 8 6 1}$ \\
Depth & 0.086 & $\mathbf{0 . 0 4 1 , 0 . 1 3 1}$ \\
Foraging tactic & 1.345 & $-0.851,3.542$ \\
Shark & 1.624 & $-9.092,12.329$ \\
Shark $\times$ Foraging tactic & -20.554 & $\mathbf{- 3 9 . 6 4 7 , - 1 . 4 6 1}$ \\
Year (2002) & -0.005 & $-0.186,0.176$ \\
Year (2003) & 0.129 & $-0.165,0.423$ \\
Year (2004) & -0.129 & $-0.350,0.092$ \\
Year (2006) & - & - \\
\hline
\end{tabular}

Significant relationships appear in bold.

existing theoretical arguments (Heithaus and Frid 2003, Frid et al. 2007b) that failure to account for predation risk may lead to flawed assessments of diving behavior and, ultimately, the role of divers in ecological communities.

Many air-breathing divers employ more than one foraging tactic, including cetaceans (e.g. Indian Ocean bottlenose dolphins Tursiops aduncus, Sargeant et al. 2007, Sargeant and Mann 2009), pinnipeds (e.g. harbour seals Phoca vitulina, Bowen et al. 2002), sea otters (e.g. California sea otter Enhydra lutris nereis, Tinker et al. 2008), marine birds (e.g. great cormorants Phalacrocorax carbo and European shags Phalacrocorax aristoteli Grémillet et al. 1998), and marine reptiles (e.g. green sea turtles Chelonia mydas, Heithaus et al. 2002). Our findings reveal that the strength and nature of diving responses of these species to predation risk may depend on their foraging mode, especially in cases where certain tactics are particularly likely to inhibit vigilance (e.g. bottom-grubbing in Indian Ocean bottlenose dolphins, Sargeant et al. 2007; benthic digging by cormorants, Grémillet et al. 1998). By implication, studies failing to consider the possibility of interaction between foraging behavioral polymorphism and threat-sensitivity in any particular breath-hold diver risk overlooking dive cycle adjustments triggered by exposure to predators and, therefore, drawing erroneous conclusions about the factors shaping diving decisions. Had we not differentiated between cropping and excavating individuals, for example, we would have concluded that tiger sharks exert little or no influence on the diving behavior of dugongs foraging over seagrass meadows.

Most studies to date have explored the influence of predation risk on a single prey behavior (Relyea 2001, Lind and Cresswell 2005). Yet, when exposed to the threat of tiger shark predation, dugongs in Shark Bay respond with a suite of behavioral adjustments: they increase their use of low profitability deep channels where sharks are less numerous and easier to evade (Wirsing et al. 2007b), shift their foraging activity to the periphery of seagrass meadows where escape into deep water is facilitated (Wirsing et al. 2007c), and decrease their reliance on excavation, which 
constrains vigilance (Wirsing et al. 2007a). By adding yet another dimension to the anti-predator behavior of dugongs - dive cycle alteration while excavating - the results of the present investigation help put to rest the notion that, like many long-lived marine mammals, dugongs are not subject to the effects of predation risk (Heithaus et al. 2008, Wirsing et al. 2008) and, more importantly, highlight the myriad ways in which predators can alter the behavior of their prey. Therefore, future studies that account for the possibility of anti-predator behavioral diversity should greatly improve our understanding of the influence of predators on individual fitness, prey populations, and community properties.

Diving adjustments by excavating dugongs under risk from sharks have potentially important implications for the composition of coastal seagrass meadows. Excavation foraging by dugongs disrupts seagrass meadow structure, creating furrows and open patches that promote succession (de Iongh et al. 1995, Preen 1995, Masini et al. 2001), while cropping does not. Thus, by inducing excavating dugongs to spend less time foraging at depth (i.e. more time at the surface scanning for predators), tiger sharks may indirectly reduce the magnitude of physical disturbance experienced by seagrass beds during periods when they are present and, as a result, inhibit colonization by fast-growing pioneering species while facilitating slow-growing competitive dominants (e.g. Amphibolis antarctica in Shark Bay). In Shark Bay and other areas where dugongs and large sharks co-occur, studies contrasting the diving profiles of and the disturbance to seagrass meadows caused by excavating dugongs during periods of low and high shark abundance should help to reveal whether predator-induced adjustments to the dugong dive cycle are sufficient to trigger this possible indirect effect in plant communities.

Previous models of diving under the risk of predation assumed that divers would alter both their time at the surface (TAS) and time at depth (TAD) per dive cycle in order to manage their risk of predation and optimize time at foraging depths (Heithaus and Frid 2003), yet we only documented a reduction in TAD driven by increased diving rate when tiger sharks were abundant. This inconsistency likely owes its existence to the fact that the mean surface time we recorded for excavating dugongs $(2.40 \mathrm{~s})$ approaches the minimum observed for diving dugongs (Churchward 2001, Chilvers et al. 2004). With little scope to further reduce their TAS, in other words, the excavating dugongs we followed could only surface more frequently in order to mitigate their risk of tiger shark predation (i.e. spend more, shorter periods inside plumes of sediment than would optimize time at the bottom foraging), producing shorter dive cycles without any change in the surface interval.

Positive correlation between shark abundance and water temperature in Shark Bay (Heithaus 2001) gives rise to the possibility that the link between dugong diving and predation risk reported here is an artifact of an underlying relationship between the dugong dive cycle and thermoregulatory costs. We suggest, however, that changes in water temperature did not strongly influence the diving behavior we observed for two reasons. First, the imposition of any thermoregulatory costs accompanying drops in ambient temperature would have been expected to alter the diving behavior of dugongs using both foraging tactics, yet only excavating individuals manifested increased TAD when water temperatures (and shark abundance) were relatively low. Second, shark-based final models of the three dive cycle parameters that varied over the course of the investigation among excavating dugongs (TAD, diving rate, DPR) were consistently superior to their temperaturebased counterparts.

Cropping and excavating dugongs target different seagrass species - leaves of temperate species and both the leaves and rhizomes of tropical species, respectively (Wirsing et al. 2007a) - so the divergent pattern of diving we observed could have been the product of changes in the quantity and/or quality of plants exploited by excavating individuals (Lanyon and Marsh 1995). We also consider this scenario to be unlikely. Optimal diving models predict positive correlation between patch quality and dive duration (Mori et al. 2002). Therefore, because the availability (biomass) of tropical leaves and rhizomes in Shark Bay peaks during the summer and then declines through the autumn and winter (Masini et al. 2001), we would have expected to observe longer dives by excavating dugongs during the height of the Austral summer if their diving behavior was driven by seagrass phenology. Instead, TAD for excavating individuals was at its lowest during summer months and increased through the autumn.

In conclusion, this field study helps to dispel the general notion, and the implicit assumption of the majority of optimal diving models, that diving behavior of large-bodied aquatic air-breathers is not influenced by predation risk. Therefore, studies that use diving behavior to infer spatiotemporal variation in characteristics of prey resources (e.g. habitat quality) or foraging effort may make incorrect conclusions if predation risk to divers varies in space and/ or time. Furthermore, in conjunction with recent studies suggesting that adjustments by individual breath-hold divers under threat of predation are condition-dependent (Frid et al. 2006, 2009), our work highlights the complexity of anti-predator decision making by diving species by showing that responses of these species to danger can vary with foraging mode. Future studies that address the drivers of this complexity should improve the performance of optimal diving models. Such studies should also yield crucial insights about the consequences of declines in predator abundance for diver behavior and, because changes to patterns of resource exploitation by these species could cascade through communities (Boyd 1997, Heithaus et al. 2008), the dynamics of aquatic ecosystems. Without this insight, those responsible for the protection of exploited aquatic systems with depleted predator populations could underestimate the importance of predation and, therefore, fail to prevent further degradation or restore ecosystem integrity.

Acknowledgements - This study is based upon work supported by grants from the National Science Foundation (OCE0526065 and OCE0745606), the National Geographic Society Expeditions Council, NSERC Canada (A6869), and the PADI Foundation. We are grateful to the Monkey Mia Dolphin Resort and the Western Australia Dept of Environment and Conservation (DEC) for logistical support, B. Sargeant for statistical advice, our many volunteers for their help in the field, and W. Cresswell for helpful comments on a previous version of this manuscript. Field research 
was conducted under the authority of Fisheries Western Australia permit 08/01 and renewals, DEC permits SF003818, SF004228, SF004542, SW008085, and renewals, and Florida International Univ. and Simon Fraser Univ. Animal Care and Use permits. This paper is contribution no. 45 of the Shark Bay Ecosystem Research Project (<www.sberp.org $>$ ).

\section{References}

Altmann, J. 1974. Observational study of behavior: sampling methods. - Behaviour 49: 227-267.

Aragones, L. et al. 2006. Dugong grazing and turtle cropping: grazing optimization in tropical seagrass ecosystems. - Oecologia 149: 635-647.

Bednekoff, P. A. and Lima, S. L. 1998. Randomness, chaos, and confusion in the study of antipredator vigilance. - Trends Ecol. Evol. 13: 284-287.

Belsley, D. A. et al. 2004. Regression diagnostics: identifying influential data and sources of collinearity. - Wiley.

Bowen, W. D. et al. 2002. Prey-dependent foraging tactics and prey profitability in a marine mammal. - Mar. Ecol. Prog. Ser. 244: $235-245$.

Boyd, I. L. 1997. The behavioural and physiological ecology of diving. - Trends Ecol. Evol. 12: 213-217.

Burnham, K. P. and Anderson, D. R. 2002. Model selection and multimodel inference: a practical information-theoretic approach, 2nd ed. - Springer.

Carbone, C. and Houston, A. I. 1996. The optimal allocation of time over the dive cycle: an approach based on aerobic and anaerobic respiration. - Anim. Behav. 51: 1247-1255.

Chilvers, B. L. et al. 2004. Diving behaviour of dugongs, Dugong dugon. - J. Exp. Mar. Biol. Ecol. 304: 203-224.

Churchward, C. A. 2001. The effect of depth and activity type on dugong (Dugongdugon) diving behaviour in Shark Bay, Western Australia. - Masters thesis, Univ. of Calgary.

de Iongh, H. H. et al. 1995. Seagrass distribution and seasonal biomass changes in relation to dugong grazing in the Moluccas, East Indonesia. - Aquat. Bot. 50: 1-19.

Dunphy-Daly, M. M. et al. 2010. Predation risk influences the diving behavior of a marine mesopredator. - Open Ecol. J. 3: 8-15.

Frid, A. et al. 2006. Do resource declines increase predation rates on North Pacific harbor seals? A behavior-based plausibility model. - Mar. Ecol. Prog. Ser. 312: 265-275.

Frid, A. et al. 2007a. Inferring prey perception of relative danger in large-scale marine systems. - Evol. Ecol. Res. 9: 635-649.

Frid, A. et al. 2007b. Dangerous dive cycles and the proverbial ostrich. - Oikos 116: 893-902.

Frid, A. et al. 2008. Do shark declines created fear-released systems? - Oikos 117: 191-201.

Frid, A. et al. 2009. Predicting synergistic effects of resources and predators on foraging decisions by juvenile Steller sea lions. - Oecologia 158: 775-786.

Gales, N. et al. 2004. Change in abundance of dugongs in Shark Bay, Ningaloo and Exmouth Gulf, Western Australia: evidence for large-scale migration. - Wildlife Res. 31: 283-290.

Grémillet, D. et al. 1998. Flexible foraging techniques in breeding cormorants, Phalacrocorax carbo, and shags, Phalacrocorax aristotelis: benthic or pelagic feeding? - Ibis 140: 113-119.

Guillemain, M. et al. 2007. Predation risk constrains the plasticity of foraging behaviour in teals, Anas crecca: a flyway-level circumannual approach. - Anim. Behav. 73: 845-854.

Hays, G. C. et al. 2001. The diving behaviour of green turtles undertaking oceanic migration to and from Ascension Island: dive durations, dive profiles and depth distribution. - J. Exp. Biol. 204: 4093-4098.

Heithaus, M. R. 2001. The biology of tiger sharks, Galeocerdo cuvier, in Shark Bay, Western Australia: sex ratio, size distribution, diet and seasonal changes in catch rates. - Environ. Biol. Fish. 61: 25-36.

Heithaus, M. R. and Frid, A. 2003. Optimal diving under the risk of predation. - J. Theor. Biol. 223: 79-93.

Heithaus, M. R. et al. 2002. Novel insights into the behavior of sea turtles from animal-borne cameras. - J. Mar. Biol. Ass. UK 82: $1049-1050$.

Heithaus, M. R. et al. 2006. Validation of a randomization procedure to assess animal habitat preferences: microhabitat use of tiger sharks in a seagrass ecosystem. - J. Anim. Ecol. 75: 666-676.

Heithaus, M. R. et al. 2008. Predicting ecological consequences of marine top predator declines. - Trends Ecol. Evol. 23: 202-210.

Houghton, J. D. R. et al. 2008. Measuring the state of consciousness in a free-living diving sea turtle. - J. Exp. Mar. Biol. Ecol. 356: $115-120$.

Houston, A. I. and Carbone, C. 1992. The optimal allocation of time during the diving cycle. - Behav. Ecol. 3: 255-265.

Johnson, D. H. 1999. The insignificance of statistical significance testing. - J. Wildlife Manage. 63: 763-772.

Kaby, U. and Lind, J. 2003. What limits predator detection in blue tits (Parus caeruleus): posture, task, or orientation? - Behav. Ecol. Sociobiol. 54: 534-538.

Kramer, D. L. 1988. The behavioral ecology of air breathing by aquatic animals. - Can. J. Zool. 66: 89-94.

Krause J. and Godin, J. G. J. 1996. Influence of prey foraging posture on flight behavior and predation risk: predators take advantage of unwary prey. - Behav. Ecol. 7: 264-271.

Lanyon, J. M. and Marsh, H. 1995. Temporal changes in the abundance of some tropical intertidal seagrasses in north Queensland. - Aquat. Bot. 49: 217-237.

Lind, J. and Cresswell, W. 2005. Determining the fitness consequences of antipredation behavior. - Behav. Ecol. 16: 945-956.

Marsh, H. et al. 1982. Analysis of stomach contents of dugongs from Queensland, Australia. - Aust. Wildlife Res. 9: 55-68.

Masini, R. J. et al. 2001. A Halodule-dominated community in a subtropical embayment: physical environment, productivity, biomass, and impact of dugong grazing. - Aquat. Bot. 71: 179-197.

Mori, Y. et al. 2002. An application of optimal diving models to diving behaviour of Brunnich's guillemots. - Anim. Behav. 64: 739-745.

Myers, R. A. and Worm, B. 2003. Rapid worldwide depletion of predatory fish communities. - Nature 423: 280-283.

Pauly, D. et al. 1998. Fishing down marine food webs. - Science 279: 860-863.

Preen, A. R. 1995. Impacts of dugong foraging on seagrass habitats: observational and experimental evidence for cultivation grazing. - Mar. Ecol. Prog. Ser. 124: 201-213.

Relyea, R. A. 2001. Morphological and behavioral plasticity of larval anurans in response to different predators. - Ecology 82: 523-540.

Sargeant, B. L. and Mann, J. 2009. Developmental evidence for foraging traditions in wild bottlenose dolphins. - Anim. Behav. 78: 715-721.

Sargeant, B. L. et al. 2007. Can environmental heterogeneity explain individual foraging variation in wild bottlenose dolphins (Tursiops sp.)? - Behav. Ecol. Sociobiol. 61: 679-688.

Soulé, M. E. et al. 2005. Strongly interacting species: conservation policy, management, and ethics. - BioScience 55: 168-176.

Thompson, D. and Fedak, M. A. 2001. How long should a dive last? A simple model of foraging decisions by breath-hold divers in a patchy environment. - Anim. Behav. 61: 287-296.

Tinker, M. T. et al. 2008. Food limitation leads to behavioral diversification and dietary specialization in sea otters. - Proc. Natl Acad. Sci USA 105: 560-565.

Wirsing, A. J. et al. 2006. Tiger shark (Galeocerdo cuvier) abundance and growth rates in a subtropical embayment: evidence from seven years of standardized fishing effort. - Mar. Biol. 149: 961-968. 
Wirsing, A. J. et al. 2007a. Can you dig it? Use of excavation, a risky foraging tactic, by dugongs is sensitive to predation danger. - Anim. Behav. 74: 1085-1091.

Wirsing, A. J. et al. 2007b. Fear factor: do dugongs (Dugong dugon) trade food for safety from tiger sharks (Galeocerdo cuvier)? - Oecologia 153: 1031-1040.
Wirsing, A. J. et al. 2007c. Living on the edge: dugongs prefer to forage in microhabitats allowing for escape from rather than avoidance of predators. - Anim. Behav. 74: 93-101.

Wirsing, A. J. et al. 2008. Seascapes of fear: evaluating sublethal predator effects experienced and generated by marine mammals. - Mar. Mamm. Sci. 24: 1-15. 